\title{
The Panorama and Outcomes of Pregnancies Within a Well-Defined Population in Rural Vietnam 1999-2004
}

\author{
Sophie Graner • Marie Klingberg-Allvin • \\ Ho Dang Phuc • Gunilla Krantz • Ingrid Mogren
}

(C) International Society of Behavioral Medicine 2008

\begin{abstract}
Background Pregnancy outcomes in the general population are important public health indicators.

Purpose The overall aim of this study was to investigate the outcomes of reported pregnancies within a well-defined population, to identify risk groups for adverse pregnancy outcomes, and to suggest preventive measures.

Method A prospective population-based cohort study of pregnant women in Bavi district, Vietnam between 1 January 1999 and 30 June 2004.

Results Pregnancy outcome was reported for 5,259 cases; $4,152(79 \%)$ resulted in a live birth, $67(1.3 \%)$ in a stillbirth, $733(14 \%)$ in an induced abortion, and $282(5.4 \%)$ in a
\end{abstract}

S. Graner $(\square) \cdot$ I. Mogren

Department of Public Health and Clinical Medicine,

Epidemiology and Public Health Sciences, Umeå University,

90187 Umeå, Sweden

e-mail: Sophie.Graner@epiph.umu.se

M. Klingberg-Allvin $\cdot$ G. Krantz

Department of Public Health Sciences,

Division of International Health Care, Karolinska Institutet,

Stockholm, Sweden

H. D. Phuc

Department of Probability and Mathematical Statistics, Institute of Mathematics,

Hanoi, Vietnam

G. Krantz

Department of Community Medicine and Public Health,

The Sahlgrenska Academy at Gothenburg University,

Gothenburg, Sweden

\section{Mogren}

Department of Clinical Sciences, Obstetrics and Gynaecology, Umeå University,

Umeå, Sweden spontaneous abortion. There was an increased risk of home delivery for women from ethnic minorities $(\mathrm{OR}=1.85 ; 95 \%$ $\mathrm{CI}=1.06-3.24)$ or with less than 6 years of schooling $(\mathrm{OR}=$ 7.36; 95\% CI=3.54-15.30). The risk of stillbirth was increased for ethnic minorities $(\mathrm{OR}=6.34 ; 95 \% \mathrm{CI}=1.33$ $30.29)$ and women delivering at home $(\mathrm{OR}=6.81 ; 95 \% \mathrm{CI}=$ 2.40-19.30). The risk of induced abortion increased with maternal age.

Conclusion Our findings emphasize the public health significance of access to adequate family planning, counselling, and maternal health care for all women. Policies should specifically target women from high-risk groups.

Keywords Pregnancy outcome · Cohort · Vietnam · Demographic surveillance systems · Population-based · Prospective

\section{Introduction}

Fertility rates and pregnancy outcomes among the general population are important public health indicators, both for assessing reproductive health status in a community and for planning health care services. Adverse pregnancy outcomes such as spontaneous abortions and stillbirths exert an impact on a woman's present and future reproductive health [1-3]. Important risk factors for adverse pregnancy outcomes are closely linked with individual factors such as previous reproductive history, intercurrent morbidity, and socioeconomic conditions and to contextual factors such as the quality of and access to maternal health care [2, 4-15]. Contextual factors are of particular importance in lowincome countries such as Vietnam where this study was conducted. In 2002, the Ministry of Health in Vietnam estimated the proportion of stillbirths at 6.1 per 1,000 live 
births and that of miscarriages at 22.4 per 1,000 live births. In general, Vietnam enjoys better public health and gender equality indicators than other countries in the same income category or in the region [16]. The legal and institutional framework is in place for reproductive health, but there are still areas of concern; for example, the access to modern contraception methods varies greatly. Women from ethnic minorities, adolescents, and the migrating labor force are identified as vulnerable groups for reproductive health complications [16].

Currently, the total fertility rate in Vietnam is the lowest ever reported (2.11 births per woman), and all methods of modern contraceptives are legal. Although not an adverse outcome, an induced abortion indicates a failure in the use of contraceptive methods $[17,18]$. Abortion has been legal in Vietnam since the 1960s, but did not became widespread until the late $1980 \mathrm{~s}$ in connection with the strictly implemented population policy of limiting births to two children per family, spaced 3-5 years apart, and delaying marriage and childbearing until at least the age of 19 [1921]. The abortion rate increased rapidly to become one of the highest in the world; in 1996, it was estimated at 83 per 1,000 women aged $15-44$ years [22, 23]. Family planning services are regulated by law and provided both in the public and private sectors. In 2003, almost $80 \%$ of women aged 15-49 years used some kind of contraception. The most common method is intrauterine device followed by withdrawal and safe periods. A minority used oral contraception. In Vietnam $6.8 \%$ of couples are sterilized and there are government incentives for individuals who undergo sterilization [24].

Women's access to reproductive health care varies widely in Vietnam. The national health care system in Vietnam is organized on the basis of community health stations (CHS), which are responsible for primary health care including family planning, surgical abortions, and delivery services. A national plan for safe motherhood, running from 2003 to 2010, has been developed to address the issues of quality and access to delivery services [6]. In the Red River Delta where the current study was performed, almost all deliveries $(98.7 \%)$ take place at a health facility and $98 \%$ of expectant mothers attend antenatal care [25].

Vietnam is currently in a transitional period with a rapidly growing economy and extensive changes within the health care system, which may affect the access to health care and maternal health outcomes. Traditionally, primary health care has been free of charge or with low fees, but some evidence indicates that the economic reform from 1986 (the doi moi) has altered the system, making primary health care less affordable, especially for the poor. The government introduced user fees in the health care systems in 1989 to allow for appropriate funding. The reform allowed, among other things, an establishment of a private sector in Vietnam, which led to a decline in the utilization of public health care. In 2001, "out of pocket" health payment represented $87.6 \%$ of the health care costs nationwide $[6,24,26]$.

This study investigated the maternal sociodemographic factors' influence on pregnancy outcomes during a specified time period in a rural district in Vietnam.

\section{Aim}

The overall aim of this study was to investigate the outcomes of all reported pregnancies within a well-defined population, to identify risk groups for adverse pregnancy outcomes, and to suggest preventive measures.

\section{Method}

The study was conducted in Bavi district, a rural setting in Ha Tay province, approximately $60 \mathrm{~km}$ north of Hanoi. The district has 240,700 inhabitants, $20 \%$ of which were randomly selected to be surveyed in the epidemiological field laboratory in Bavi (FilaBavi) where population-based demographic and health data have been collected since 1 January 1999. The data collection procedure has been described in detail elsewhere [27]. The majority ethnic group is Kinh $(96 \%)$, but other ethnic groups such as Muong and Dao are also represented. The main source of income is farming $(80 \%)$; other sources include small trade and forestry. Most health care is publicly administered, but the area also has a number of private practitioners [27]. There are 32 CHS, three outpatient clinics (so-called policlinics), and one district hospital, which provides surgical facilities. Each CHS is generally staffed with a medical doctor, assistant doctors, nurses, and midwives and equipped with oral and intravenous drugs. Women in need of more qualified medical care are referred to the district hospital [28].

Three baseline surveys have been performed in the area within the management of the field laboratory $(1999,2001$, and 2003), recording socioeconomic data such as education, income, and marital status. All selected households are visited every 3 months by a female surveyor from the field laboratory, and various data are collected from the individual women: the first day of the last menstrual period (LMP), ongoing pregnancy, and pregnancy outcome. In the current study, information on socioeconomic factors and household information from the baseline survey in 2001 was used.

The FilaBavi was designed in order to reduce selection bias by random selection of households in the catchment area [27]. Recall bias was avoided by a relatively short time period between the events and the data collection (less than 
6 months). Maternal recall of pregnancy outcome has been shown to be minimal after 3-9 years [29]. To ensure internal validity, the data were regularly cross-checked by another surveyor revisiting the households and the field laboratory supervisors.

\section{The Study Population}

All women with a reported pregnancy in the database from 1 January 1999 to the time of data extraction in October 2004 were included in the study, a total of 5,845 pregnancies. Six cases with LMP after 30 June 2004 were excluded, as was one case with an obviously erroneous maternal age (2.5 years), resulting in 5,838 pregnancies with a LMP between 20 March 1998 and 26 May 2004. Two cases of negative gestational age were recoded as gestational age missing. The final dataset contained information on socioeconomic background factors such as maternal age, ethnicity, marital status education, occupation, income category, area of residence, LMP, date of pregnancy outcome, date of birth, and place of delivery.

The average yearly population of women aged 1544 years in Bavi was 13,332, contributing to a total of 65,924 person-years between January 1999 and June 2004.

Ethical approval for the epidemiological surveillance, including vital statistics, was granted by the Ethics Committee at Umeå University (ref. 02-420).

\section{Definitions and Abbreviations}

\section{Dependent Variables}

Stillbirth was defined as the birth of a dead fetus, as reported by the woman with a gestational age equal to or more than $24+0$ weeks (i.e., 169 days).

Spontaneous abortion was defined as a noninduced termination of pregnancy at or before $23+6$ gestational weeks (i.e., 168 days).

Menstrual regulation (MR) is a term commonly used in Vietnam to denote a manual vacuum aspiration of the uterus in a probable (but not always confirmed) early pregnancy. Menstrual regulation was defined as the pregnancy outcome when reported as such by the woman. In the logistic regression analysis, menstrual regulation was included with all other methods of induced abortion.

Induced abortion was defined as any induced termination of the pregnancy as reported by the woman, except for menstrual regulation, which was categorized separately.

Place of delivery was classified as reported by the woman. In the logistic regression analysis, place of delivery was regrouped into either facility-based (CHS or hospital) or home-based (including the house of a traditional birth attendant $[\mathrm{TBA}])$.

\section{Independent Variables}

Last menstrual period (LMP) was defined as the date of the first day of bleeding in the menstrual period preceding the pregnancy.

Gestational age was defined as the number of days between the date of LMP and the date of the pregnancy outcome.

Interpregnancy interval was defined as the number of months reported between the outcome of a previous pregnancy and the date of LMP for the subsequent pregnancy. A month was estimated as 30.4 days.

Minority was defined as belonging to any ethnic group other than Kinh.

Maternal age was defined as the age of the woman at the date of reported pregnancy outcome.

Economic status was categorized on household level as reported by the head of the village community. The annual income per person per year was $<90$ USD in low-income households, 91-135 USD in average-income households, and $>136$ USD in high-income households.

Area of residence was categorized as reported by the local authorities. The areas differ in mean income level and main source of income distance to health care.

Stillbirth incidence was defined as the number of stillbirths per 1,000 live births and stillbirths.

\section{Statistics}

Statistical analysis was performed using SPSS version 13.0. Mean values and their standard deviations (SD) were calculated for parametric data. Bivariate analysis of categorical data was used to obtain crude odds ratios (COR) and their 95\% confidence intervals $(95 \% \mathrm{CI})$. Statistically significant variables were then entered stepwise in the multivariate logistic regression analysis to obtain adjusted ORs (AOR) and their 95\%CI.

\section{Results}

A total of 5,838 pregnancies reported by 4,396 women were included in the study over the 5-year period. Information on pregnancy outcome was missing for 579 women. However, 388 of these had a LMP later than 31 March 2004, and therefore, the pregnancies were assumed to be ongoing at the time of data extraction; thus, $3.3 \%$ of the total cases were lost to follow-up. Pregnancy outcome was reported for 5,259 cases; 4,152 of these (79.0\%) resulted in a live birth, $67(1.3 \%)$ in a stillbirth, $733(14 \%)$ in an induced abortion, and $282(5.4 \%)$ in a spontaneous abortion. Other pregnancy outcomes were reported for 25 cases $(0.5 \%)$, including extrauterine pregnancy $(n=23)$ and 
molar pregnancy $(n=2)$. The socioeconomic characteristics for each specified pregnancy outcome are shown in Table 1.

The COR for each independent variable and their associated $95 \% \mathrm{CI}$ are presented in Table 2 for induced and spontaneous abortions, stillbirths, and birth place outside health care services.

First-time marriage was reported by 530 women during the study period (mean age and SD $20.8 \pm 3.2$ years), and $70.9 \%$ of these $(n=376)$ reported a pregnancy within 1 year of marriage. Mean age and SD at first child was $22.4 \pm$ 3.4 years. Among the women who married for the first time during the study period, the pregnancy outcome was $91.8 \%$ live births, $0.9 \%$ stillbirths, $0.5 \%$ induced abortions, $6.4 \%$ spontaneous abortions, and $0.5 \%$ other outcomes.

The mean interpregnancy interval and SD for all women $(n=1,237)$ between the first and second pregnancy was $16.9 \pm 11.4$ months. The mean interpregnancy interval and SD between two live born children $(n=587)$ was $19.7 \pm$ 9.9 months. During the 5-year study period, 1,237 women (28\%) reported two pregnancies, $191(4.4 \%)$ reported three pregnancies, and $13(0.3 \%)$ reported four. Figure 1 shows the proportions of live birth, stillbirth, induced abortion, and spontaneous abortion in relation to the number of pregnancies during the study period among women with subsequent pregnancies $(n=1441)$.

\section{Induced Abortions}

The induced abortion rate during 1999-2000 was estimated at 20 per 1,000 women aged 15-44 years; it decreased rapidly to seven per 1,000 women in 2001 , and remained low during 2002 and 2003 (six and five per 1,000 women, respectively).

Figure 2 shows the yearly induced abortion rates per 1,000 person-years, by age strata. Women aged $25-34$ years had the highest rates and the most rapid decline, while the rate for women aged $\leq 19$ years remained very low and stable throughout the study period.

The majority of induced abortions (82\%) were reported as menstrual regulation with a mean gestational age and $\mathrm{SD}$

Proportion of live births, stillbirths, induced and spontaneous abortions in relation to number of pregnancies.

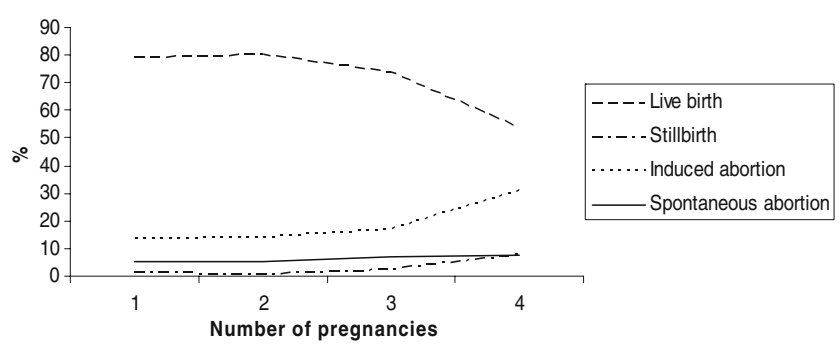

Fig. 1 Proportion of live births, stillbirths, induced and spontaneous abortions in relation to number of pregnancies

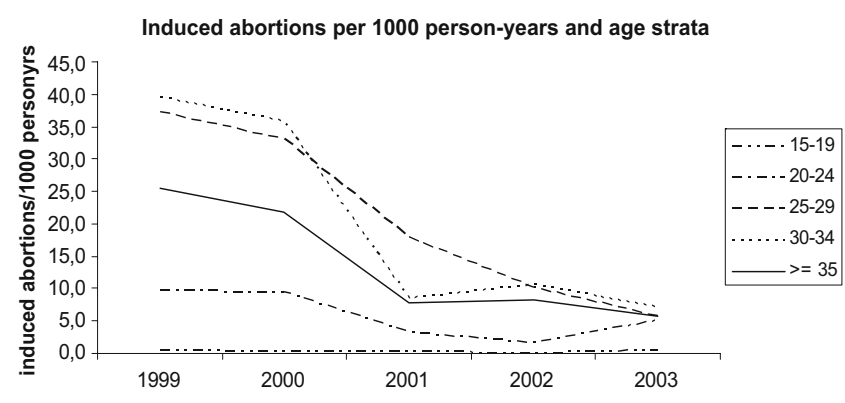

Fig. 2 Induced abortions per 1,000 person-years and age strata

of $44.8 \pm 14.4$ days. The mean gestational age and SD for other methods of induced abortion was $79.3 \pm 36.6$ days.

Maternal age, marital status, and occupation all remained significant in the multivariate analysis. The risk of induced abortion increased gradually with maternal age, from 4.30 $(95 \% \mathrm{CI}=1.56-11.79)$ for women aged $20-24$ years to 99.6 $(95 \% \mathrm{CI}=36.65-270.73)$ for women aged $\geq 35$ years compared to women $<20$ years. Single mothers had less induced abortions compared to married women $(\mathrm{AOR}=0.06 ; 95 \%$ $\mathrm{CI}=0.01-0.42)$. Farmers $(\mathrm{AOR}=1.70 ; 95 \% \mathrm{CI}=1.18-2.46)$ and self-employed women $(\mathrm{AOR}=2.94 ; 95 \% \mathrm{CI}=1.94$ 4.45) had increased risk compared with employed women (data not presented in table).

\section{Stillbirths}

The overall stillbirth incidence for the study period was calculated at 15.9 per 1,000 births with a mean gestational age and SD of $235 \pm 41$ days. In the multivariate analysis, ethnicity was included because it is known from previous studies to be a risk factor. Belonging to an ethnic minority $(\mathrm{AOR}=6.34 ; 95 \% \mathrm{CI}=1.33-30.29)$, delivering at home ( $\mathrm{AOR}=6.81 ; 95 \% \mathrm{CI}=2.40-19.30$ ), belonging to an averageincome category $(\mathrm{AOR}=3.20 ; 95 \% \mathrm{CI}=1.42-7.19)$, or living in the highlands ( $\mathrm{AOR}=4.46 ; 95 \% \mathrm{CI}=1.34-14.79)$ was associated with an increased risk of stillbirth (data not presented in table).

\section{Spontaneous Abortions}

The mean gestational age and SD was $81 \pm 31$ days. Maternal age was the only significant determinant for a spontaneous abortion in the bivariate analysis. Maternal age of $<20$ years $(\mathrm{COR}=1.79 ; 95 \% \mathrm{CI}=1.25-2.60)$ or $\geq 35$ years $(\mathrm{COR}=2.07 ; 95 \% \mathrm{CI}=1.37-3.13)$ was associated with an almost doubled risk of spontaneous abortion in comparison with a maternal age of 20-24 years (Table 2).

Place of Delivery

Among women reporting a live birth or a stillbirth, 97.3\% had delivered at a CHS or a hospital, while $2.7 \%$ had delivered at home or at the house of a TBA. Most deliveries 


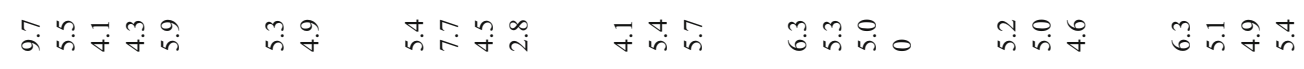

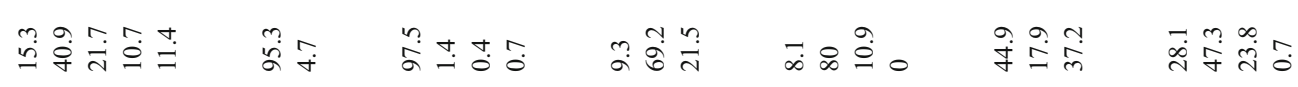
भำ ซำ

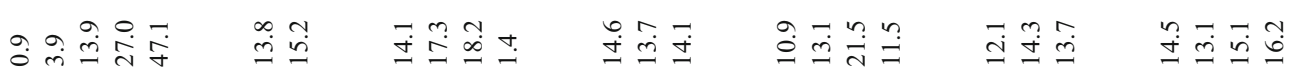

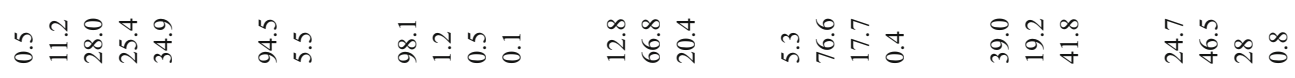

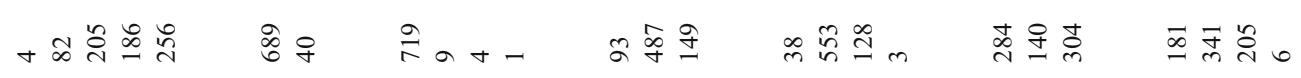

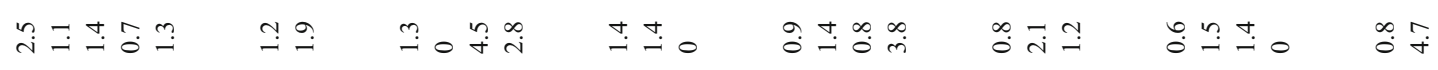

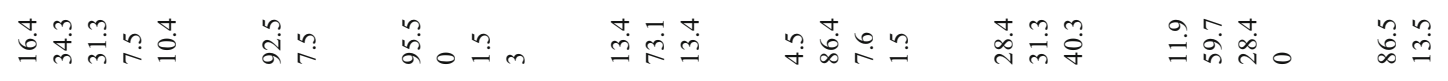

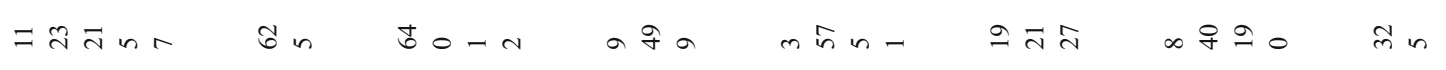

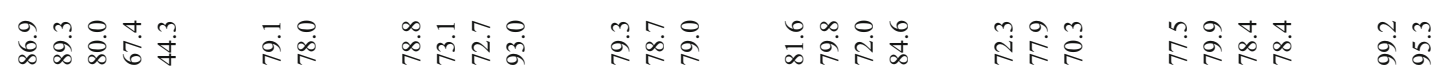

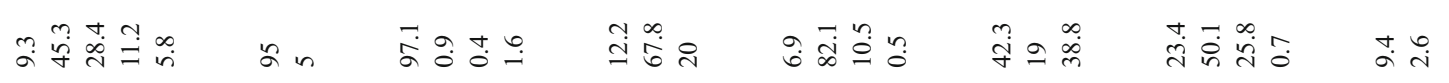

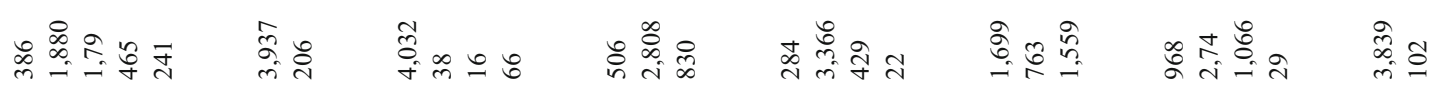

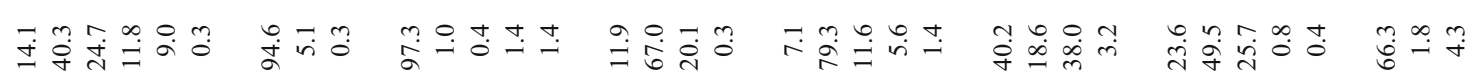

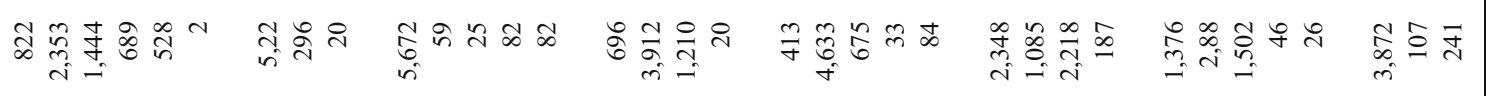

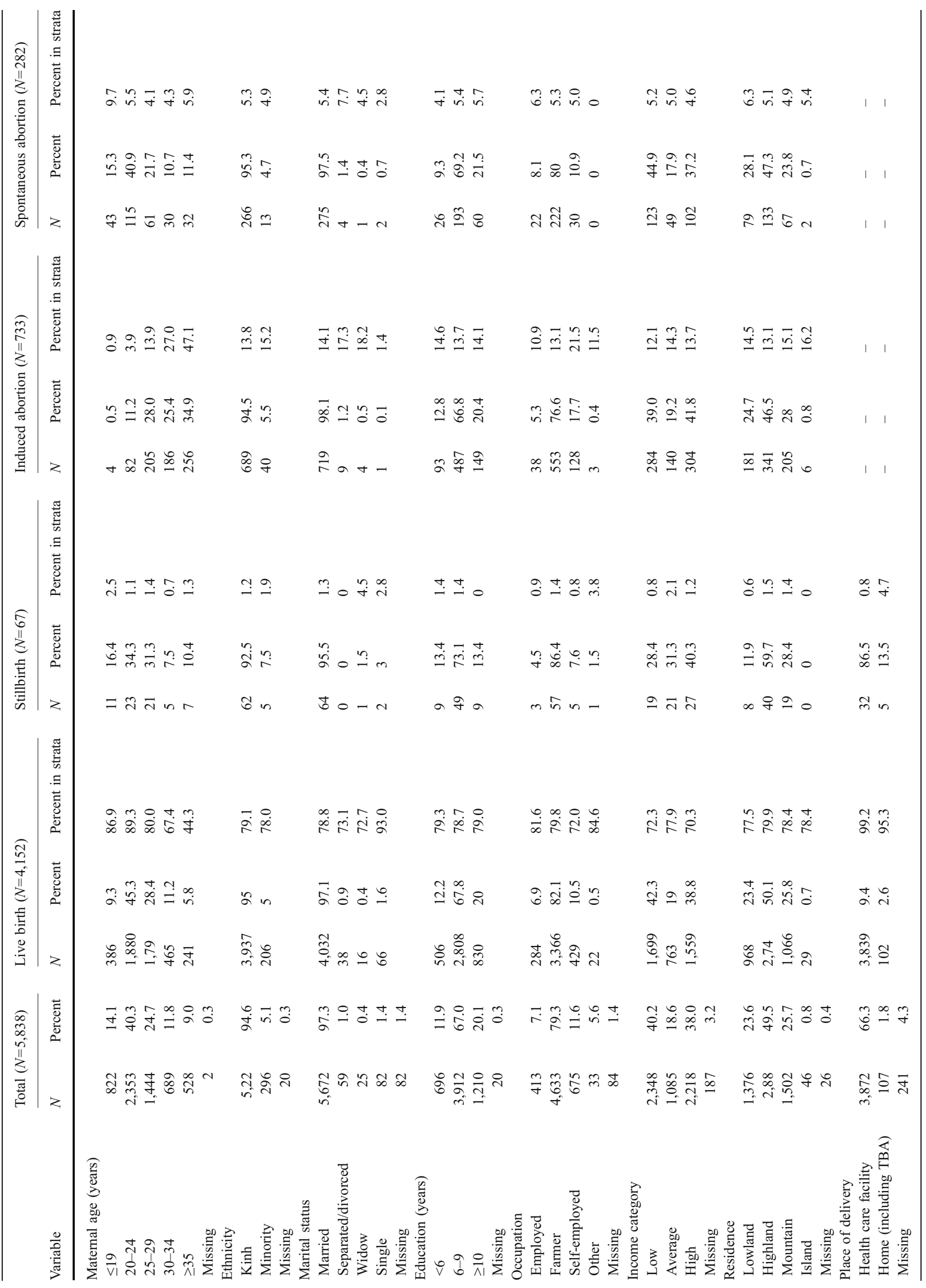




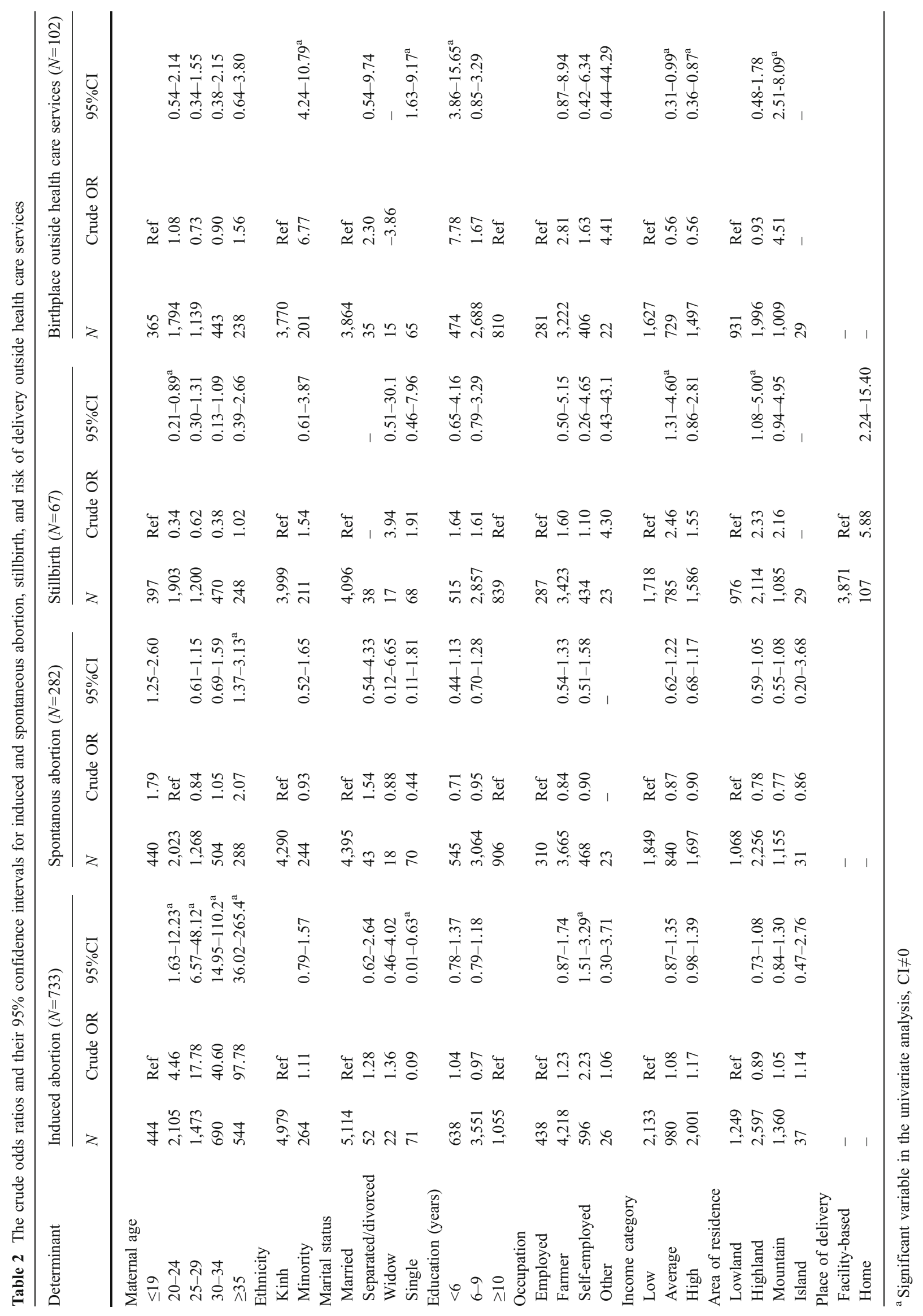


(97.8\%) were assisted by a doctor, a midwife, or a medically trained private health care provider. Around $1 \%$ was assisted by a TBA and $0.1 \%$ of cases had no assistance. Among the study population, the mean distance to a CHS was $1.7 \mathrm{~km}$ (range $=0.01-9 \mathrm{~km})$.

The multivariate analysis showed that women from ethnic minorities, women with less than 6 years of education, and women living in the mountainous area had an increased risk of delivering their child outside the health care system. Marital status and income category were significant in the bivariate analysis, but their effect was modified by the educational level (Table 3 ).

\section{Discussion}

We found in this study that $80 \%$ of all pregnancies resulted in a live birth and the overall incidence of stillbirth was estimated at 15.9 per 1,000 births. Women from ethnic minorities presented increased risks of home delivery and associated stillbirth. The induced abortion rate decreased during the study period and was most prominent for women aged 25-34 years. The data in this analysis provide robust, current estimations of the prevalence and rates of specified pregnancy outcomes which contribute to our understanding of the state of maternal health in Vietnam.
Methodological Considerations

\section{Internal Validity}

The study setting in FilaBavi minimized challenges to internal validity.

\section{External Validity}

The presence of a field laboratory in the community will probably have increased the general awareness of health care-related issues. It may be assumed that the population in Bavi in general is better informed about health care; a matter which might affect the general health situation, compared to other parts of rural Vietnam. This might reduce the generalizability of the study; however, we believe that the effect is marginal as numerous other health research and implementation initiatives are ongoing in different parts of the country.

\section{Comparison with Other Studies}

The overall proportions of the specified outcomes in this survey are similar to those found in a retrospectively collected population-based survey conducted in Vietnam in 1994, which include 3,954 pregnancies (live birth $81 \%$,

Table 3 Adjusted odds ratios and their $95 \%$ confidence intervals for sociodemographic determinants for delivering outside a health care facility

\begin{tabular}{|c|c|c|c|c|c|c|c|c|}
\hline \multirow[t]{2}{*}{ Determinant } & \multicolumn{2}{|c|}{ Model 1} & \multicolumn{2}{|c|}{ Model 2} & \multicolumn{2}{|c|}{ Model 3} & \multicolumn{2}{|c|}{ Model 4} \\
\hline & AOR & $95 \% \mathrm{CI}$ & AOR & $95 \% \mathrm{CI}$ & AOR & $95 \% \mathrm{CI}$ & AOR & $95 \% \mathrm{CI}$ \\
\hline \multicolumn{9}{|l|}{ Ethnicity } \\
\hline Kinh & Ref & & Ref & & Ref & & Ref & \\
\hline Minority & 6.39 & $1.17-7.10^{\mathrm{a}}$ & 5.05 & $3.11-8.22^{\mathrm{a}}$ & 4.94 & $2.99-8.17^{\mathrm{a}}$ & 1.85 & $1.06-3.24^{\mathrm{a}}$ \\
\hline \multicolumn{9}{|l|}{ Marital status } \\
\hline Married & Ref & & Ref & & Ref & & Ref & \\
\hline Separated/divorced & 2.06 & $0.47-9.00$ & 1.82 & $0.40-8.17$ & 1.80 & $0.39-8.20$ & 1.90 & $0.37-8.47$ \\
\hline Widow & - & - & - & - & - & - & - & - \\
\hline Single & 2.88 & $1.17-7.10^{\mathrm{a}}$ & 2.07 & $0.83-5.19$ & 1.96 & $0.77-4.97$ & 1.90 & $0.74-4.87$ \\
\hline \multicolumn{9}{|l|}{ Education (years) } \\
\hline$<6$ & & & 6.20 & & 5.64 & & 7.36 & $3.54-15.30^{\mathrm{a}}$ \\
\hline $6-9$ & & & 1.63 & $3.05-12.62^{\mathrm{a}}$ & 1.48 & $2.75-11.55^{\mathrm{a}}$ & 1.90 & $0.95-3.81$ \\
\hline$\geq 10$ & & & Ref & $0.82-3.22$ & Ref & $0.75-2.95$ & Ref & \\
\hline \multicolumn{9}{|l|}{ Income category } \\
\hline Low & & & & & Ref & & Ref & \\
\hline Average & & & & & 0.71 & $0.40-1.28$ & 0.72 & $0.40-1.31$ \\
\hline High & & & & & 0.65 & $0.41-1.02$ & 0.57 & $0.36-0.90$ \\
\hline \multicolumn{9}{|l|}{ Area of residence } \\
\hline Lowland & & & & & & & Ref & \\
\hline Highlands & & & & & & & 0.81 & $0.42-1.56$ \\
\hline Mountains & & & & & & & 3.82 & $2.04-7.15^{\mathrm{a}}$ \\
\hline Islands & & & & & & & - & - \\
\hline
\end{tabular}

$N=4,219 ;$ live and stillbirths included in the models

${ }^{a}$ Significant result, $\mathrm{CI} \neq 0$ 
miscarriage or stillbirth $6 \%$, induced abortion $13 \%$ ) [20]. It is striking that the pregnancy outcomes are similar between the two surveys, taking into consideration the rapid economical changes that Vietnam has undergone during the last decade. The similar findings in these two studies indicate that the primary health services have kept their standard despite the decreasing financial support. The mean age at first marriage and childbearing, as well as the interpregnancy intervals, are comparable to the results reported in other studies from Vietnam [20, 25]. The proportion of spontaneous abortions $(6.4 \%)$ in the subgroup of women who married for the first time may be regarded as an indication of the prevalence of miscarriage where the intention is to reach a live birth.

There are, to the best of our knowledge, no previously published data on age-specific rates of induced abortion in Vietnam. The age-specific rates showed that women aged 25-34 years made the greatest contribution to the induced abortions, and there was a prominent reduction in the induced abortion incidence during the study period, especially in this age group (Fig. 2). For young women (15-19 years), the rates remained low and stable. The annual incidence of induced abortion was substantially lower than previously published data gathered in Vietnam in 1996 (83 per 1,000 women) [22]. Our results are most probably underestimates, since an induced abortion might be culturally and personally sensitive to report. There is, however, no reason to believe that the underreporting should change over time and to a similar degree in all age categories, and hence the reduction is probably a valid finding, which needs further exploration.

Our finding that there is a decrease in live births after the second pregnancy (Fig. 1), which is almost mirrored by an increase in induced abortions, might explain the increasing rates with maternal age. A possible explanation is that induced abortions are used as a method of family planning especially among married women with two children. Women in Vietnam still have a limited sex-negotiating power and unprotected sex within marriage is common, few men take responsibility for the contraception method used $[16,24]$. The reduced rate during the study period might be explained by an improved access to modern methods of contraception as well as an eased implementation of the two-child policy which was officially abolished in 2003. Previous studies in Vietnam and elsewhere show that the increased use of contraception reduces the abortion rate [17, 19-21, 30]. Official Vietnamese data show a reduction in induced abortions and an increase in the use of modern contraceptive methods between 2000 and 2005 [31, 32]. The finding that married women with increasing age had more abortions than young single mothers might be considered surprising but could be explained by the fact that young women that become pregnant chose to keep the pregnancy and marry their partner. In summary, the induced abortion rate in Vietnam is probably declining, but it seems that induced abortions may still be used as a method of family planning, especially among older women.

The incidence of stillbirth (Table 2) was substantially higher than previously reported for Vietnam (six to 10.0 per 1,000 births) [32, 33]. Minority ethnic groups were at increased risk of stillbirth and home delivery. Women with less than 6 years of education had an increased risk for home delivery. These findings correspond well with other studies in which women with less education or from nonKinh-dominated areas were found to be more likely to deliver at home or with an untrained attendant $[16,34]$. These results point to a structural public health problem within this context and indicate a possible mistrust or lack of access to maternal health care among some groups of women. We assume that the absolute numbers of stillbirths have been underestimated due to the sensitivity of the issues of infant death and stillbirth, as has been shown elsewhere [35, 36]. The Vietnamese tradition of not considering an infant fully human before 1 year of age and the reluctance to report the death of a child exceeding the two-child policy might constitute additional factors [36]. Nevertheless, our estimations were higher than other sources and the quarterly follow-up system of FilaBavi has previously been shown to detect the highest numbers of deaths in the community and to produce more valid data than the official sources $[35,36]$.

\section{Conclusion}

The pregnancy outcomes in this study are coherent with previous studies from Vietnam; however, the results indicate that women from ethnic minorities or with less than 6 years education are more at risk for home deliveries and associated stillbirth, and further studies should aim to investigate this. The study further indicates that induced abortions might be used as a method for family planning. This emphasizes the public health significance of access to adequate family planning, counselling, and maternal health care for all women. Policies that target women from highrisk groups are needed. Actions to be suggested include increasing the number of women from ethnic minorities as health care providers and improving the collaboration between TBAs and the national health care services. It is also necessary to assure information and access to modern contraceptive methods universally and strengthen the counselling on contraceptive methods in association with an induced abortion.

Acknowledgements The authors would like to thank all participating women as well as Drs. NT Chuc, A Johansson, and DL Huong for the valuable contributions. The demographic surveillance site is 
funded by SIDA/SAREC Stockholm. Sophie Graner received a planning grant from SIDA/SAREC 2004.

Competing interests None declared.

\section{References}

1. Basso O, Olsen J, Christensen K. Risk of preterm delivery, low birthweight and growth retardation following spontaneous abortion: a registry-based study in Denmark. Int J Epidemiol. 1998;27 (4):642-6.

2. El-Bastawissi AY, Sorensen TK, Akafomo CK, Frederick IO, Xiao R, Williams MA. History of fetal loss and other adverse pregnancy outcomes in relation to subsequent risk of preterm delivery. Matern Child Health J. 2003;7(1):53-8.

3. Klier CM, Geller PA, Ritsher JB. Affective disorders in the aftermath of miscarriage: a comprehensive review. Arch Womens Ment Health. 2002;5(4):129-49.

4. Ahmed F. Unmarried mothers as a high-risk group for adverse pregnancy outcomes. J Community Health. 1990;15(1):35-44.

5. Conde-Agudelo A, Belizan JM, Diaz-Rossello JL. Epidemiology of fetal death in Latin America. Acta Obstet Gynecol Scand. 2000;79(5):371-8.

6. Duong DV, Binns CW, Lee AH. Utilization of delivery services at the primary health care level in rural Vietnam. Soc Sci Med. 2004;59(12):2585-95.

7. Duong DV, Lee AH, Binns CW. Measuring preferences for delivery services in rural Vietnam. Birth. 2005;32(3):194-202.

8. Gibbs RS. The relationship between infections and adverse pregnancy outcomes: an overview. Ann Periodontol. 2001;6 (1):153-63.

9. Kramer MS. The epidemiology of adverse pregnancy outcomes: an overview. J Nutr. 2003;133(5 Suppl 2):1592S-6S.

10. Kramer MS. Maternal nutrition and adverse pregnancy outcomes: lessons from epidemiology. Nestle Nutr Workshop Ser Pediatr Program. 2005;55:1-10. discussion 11-5.

11. Nybo Andersen AM, Wohlfahrt J, Christens P, Olsen J, Melbye M. Maternal age and fetal loss: population based register linkage study. BMJ. 2000;320(7251):1708-12.

12. Pasupathy D, Smith GC. The analysis of factors predicting antepartum stillbirth. Minerva Ginecol. 2005;57(4):397-410.

13. Say L, Donner A, Gulmezoglu AM, Taljaard M, Piaggio G. The prevalence of stillbirths: a systematic review. Reprod Health. 2006;3:1.

14. Sheiner E, Levy A, Katz M, Mazor M. Pregnancy outcome following recurrent spontaneous abortions. Eur J Obstet Gynecol Reprod Biol. 2005;118(1):61-5.

15. Wisborg K, Kesmodel U, Henriksen TB, Hedegaard M, Secher NJ. A prospective study of maternal smoking and spontaneous abortion. Acta Obstet Gynecol Scand. 2003;82(10):936-41.

16. Rohland K, Konishi A, Brown D, Lessard G-M. Vietnam country gender assessment. World Bank group; 2006.
17. Le LC, Magnani R, Rice J, Speizer I, Bertrand W. Reassessing the level of unintended pregnancy and its correlates in Vietnam. Stud Fam Plann. 2004;35(1):15-26.

18. Nguyen TM, Chongsuvivatwong V, Geater A, Prateepchaikul L. Characteristics of repeat aborters in Vietnam. Southeast Asian J Trop Med Public Health. 2000;31(1):167-72.

19. Hoa HT, Toan NV, Johansson A, Hoa VT, Hojer B, Persson LA. Child spacing and two child policy in practice in rural Vietnam: cross sectional survey. BMJ. 1996;313(7065):1113-6.

20. Johansson A, Hoa HT, Lap NT, Diwan V, Eriksson B. Population policies and reproductive patterns in Vietnam. Lancet. 1996;347 (9014):1529-32.

21. Le Thi Nham T, Mai Huy B, Johansson A, Hoang Thi H. Women's experience of family planning in two rural communes in Vietnam. Arrows Change. 1995;1(1):3-4.

22. Henshaw SK, Singh S, Haas T. The incidence of abortion worldwide. Int Fam Plann Perspect. 1999;25(Suppl):S30-8.

23. WHO. Abortion in Vietnam; An assessment of policy, programme and research issues; 1999. http://who.int/reproductive-health/ publications/HRP_ITT_99_2/index.html.

24. ARROW. Women of the world: laws and policies affecting their reproductive rights. Malaysia: Center for Reproductive Rights, Asian-Pacific Resource and Research Centre for Women; 2005. ISBN:1-890671-29-0.

25. DHS. Demographic and health survey Vietnam 2002; 2003.

26. Khe ND, Toan NV, Xuan LT, Eriksson B, Hojer B, Diwan VK. Primary health concept revisited: where do people seek health care in a rural area of Vietnam? Health Policy. 2002;61(1):95-109.

27. Chuc NT, Diwan V. FilaBavi, a demographic surveillance site, an epidemiological field laboratory in Vietnam. Scand J Public Health Suppl. 2003;62:3-7.

28. $\mathrm{MoH}$. National standards and guidelines for reproductive services. Vietnam, Hanoi: Ministry of health; 2003.

29. Sou SC, Chen WJ, Hsieh WS, Jeng SF. Severe obstetric complications and birth characteristics in preterm or term delivery were accurately recalled by mothers. J Clin Epidemiol. 2006;59 (4):429-35.

30. Marston C, Cleland J. Relationships between contraception and abortion: a review of the evidence. Int Fam Plann Perspect. 2003;29(1):6-13.

31. MoH. Health statistics year book 2000, Hanoi: Ministry of health, health statistics and information division; 2000.

32. MoH. Health statistics year book 2005 Hanoi: Ministry of health, health statistics and information division; 2005.

33. Nguyen TH, Chongsuvivatwong V. Impact of prenatal care on perinatal mortality. Southeast Asian J Trop Med Public Health. 1997;28(1):55-61.

34. Bale B. Safe motherhood; towards safe delivery, case studies from Quang Xuong District. USA: Save the Children; 1999.

35. Huong DL, Minh HV, Byass P. Applying verbal autopsy to determine cause of death in rural Vietnam. Scand J Public Health Suppl. 2003;62:19-25.

36. Huy TQ, Long NH, Hoa DP, Byass P, Ericksson B. Validity and completeness of death reporting and registration in a rural district of Vietnam. Scand J Public Health Suppl. 2003;62:12-8. 